\title{
OPEN Dissociation of disease onset, progression and sex differences from androgen receptor levels in a mouse model of amyotrophic lateral sclerosis
}

\author{
Doris Tomas ${ }^{1,3}$, Victoria M. McLeod ${ }^{1,3}$, Mathew D. F. Chiam ${ }^{1}$, Nayomi Wanniarachchillage ${ }^{1}$, \\ Wah C. Boon ${ }^{1} \&$ Bradley J. Turner ${ }^{1,2 \bowtie}$
}

Amyotrophic lateral sclerosis (ALS) is an adult-onset neurodegenerative disorder caused by loss of motor neurons. ALS incidence is skewed towards males with typically earlier age of onset and limb site of onset. The androgen receptor (AR) is the major mediator of androgen effects in the body and is present extensively throughout the central nervous system, including motor neurons. Mutations in the AR gene lead to selective lower motor neuron degeneration in male spinal bulbar muscular atrophy (SBMA) patients, emphasising the importance of AR in maintaining motor neuron health and survival. To evaluate a potential role of AR in onset and progression of ALS, we generated SOD $1^{\text {G93A }}$ mice with either neural AR deletion or global human AR overexpression. Using a Cre-LoxP conditional gene knockout strategy, we report that neural deletion of AR has minimal impact on the disease course in SOD $1^{\text {G93A }}$ male mice. This outcome was potentially confounded by the metabolically disrupted Nestin-Cre phenotype, which likely conferred the profound lifespan extension observed in the SOD ${ }^{693 A}$ double transgenic male mice. In addition, overexpression of human AR produced no benefit to disease onset and progression in SOD ${ }^{\mathrm{G} 93 \mathrm{~A}}$ mice. In conclusion, the disease course of SOD $1{ }^{\mathrm{G} 93 \mathrm{~A}}$ mice is independent of AR expression levels, implicating other mechanisms involved in mediating the sex differences in ALS. Our findings using Nestin-Cre mice, which show an inherent metabolic phenotype, led us to hypothesise that targeting hypermetabolism associated with ALS may be a more potent modulator of disease, than AR in this mouse model.

Amyotrophic lateral sclerosis (ALS) is a fatal progressive neurodegenerative disorder in which upper and lower motor neurons die, leading to muscle atrophy and ultimately respiratory failure ${ }^{1}$. ALS shows increased incidence, a younger age and predominantly limb onset in males ${ }^{2-4}$. Higher incidence of ALS has been identified among professional athletes and soccer players ${ }^{5-8}$ which could be linked to higher prenatal testosterone exposure ${ }^{9-11}$. The biological actions of androgens are mediated by the androgen receptor (AR), a nuclear steroid hormone receptor expressed within tissues throughout the body including the central nervous system (CNS) ${ }^{12}$. The adult onset neurodegenerative disorder, spinal bulbar muscular atrophy (SBMA), is caused by trinucleotide repeat expansions in the $A R$ gene, resulting in selective lower motor neuron degeneration in males ${ }^{13}$. This evidence supports a pivotal role for androgens and AR in motor neuron health.

Animal models of ALS reflect the sex differences observed clinically ${ }^{14,15}$. The mutant superoxide dismutase 1 $\left(\mathrm{SOD} 1^{\mathrm{G} 93 \mathrm{~A}}\right)$ mouse is the most well characterised and commonly used model of ALS ${ }^{16}$. Studies into the mechanisms by which sex influences ALS have to date, largely focused on manipulation of hormones. Firstly, castration in male SOD $1^{\mathrm{G} 93 \mathrm{~A}}$ mice does not modify disease course ${ }^{17,18}$. Several confounds to castration exist. It may lead to the disruption of other hormone sources and steroidogenesis pathways, such as progesterone and estrogens. Alternatively, the adrenal glands provide another source of androgens ${ }^{19}$. Blockade of AR by the anti-androgen,

${ }^{1}$ Florey Institute of Neuroscience and Mental Health, University of Melbourne, 30 Royal Parade, Parkville, VIC 3052, Australia. ${ }^{2}$ Perron Institute for Neurological and Translational Science, Queen Elizabeth Medical Centre, Nedlands, WA 6150, Australia. ${ }^{3}$ These authors contributed equally: Doris Tomas and Victoria M. McLeod. ${ }^{\bowtie}$ email: bradley.turner@florey.edu.au 
(a)

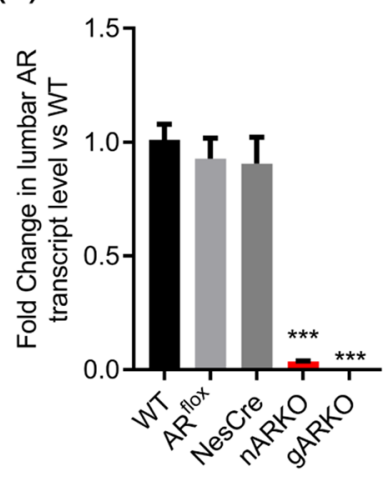

(b)

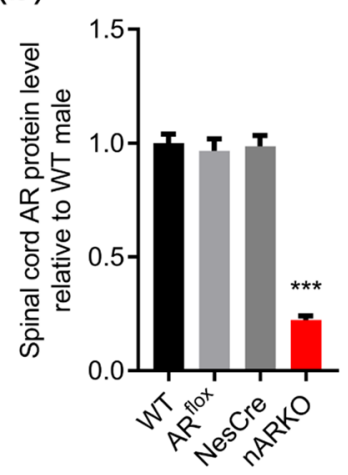

(c)

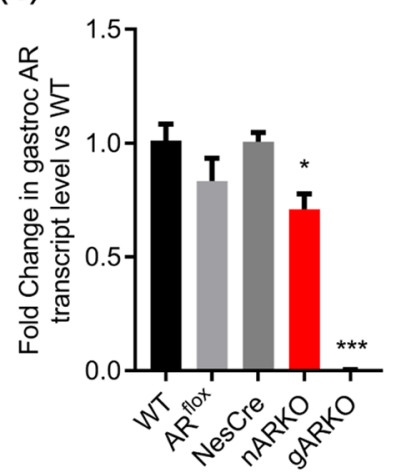

(d)

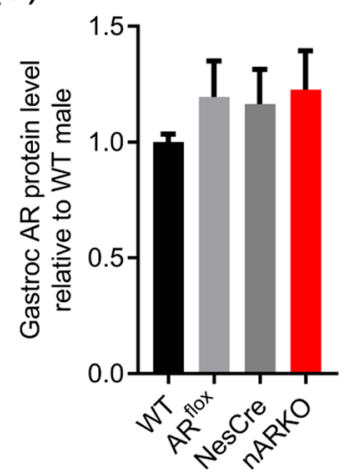

(e)
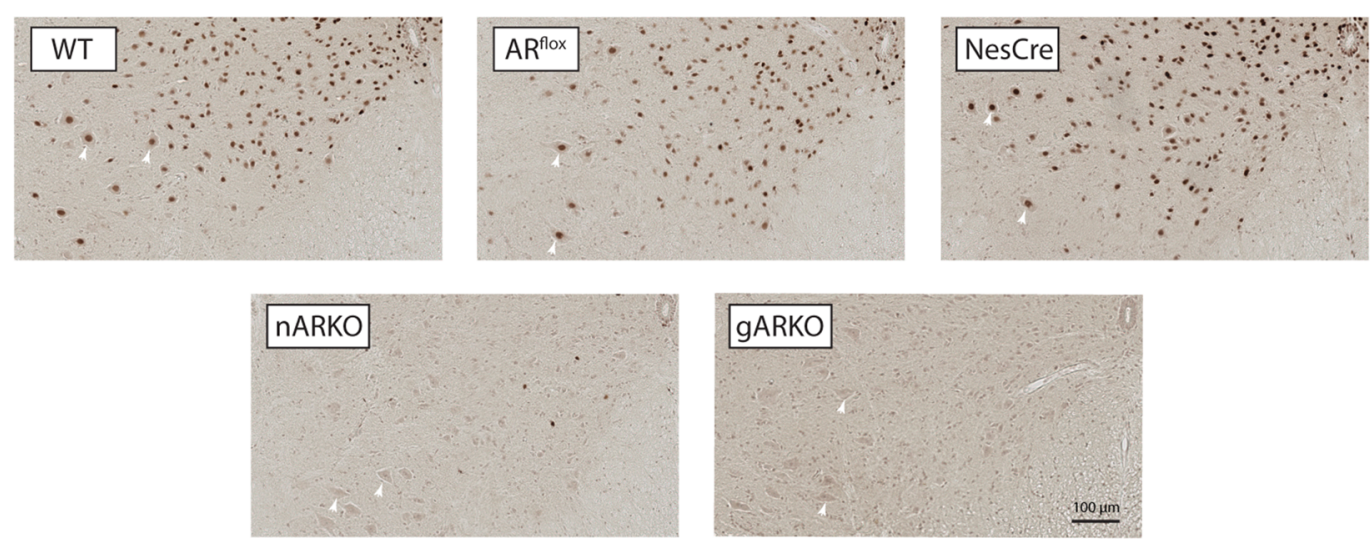

(f)

(g)

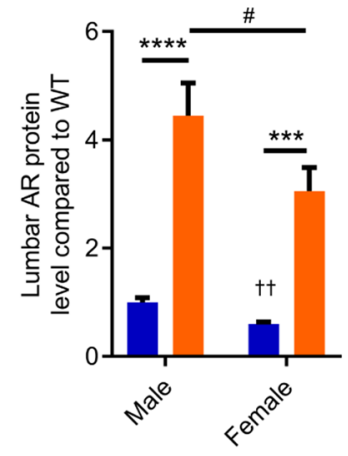

(h)

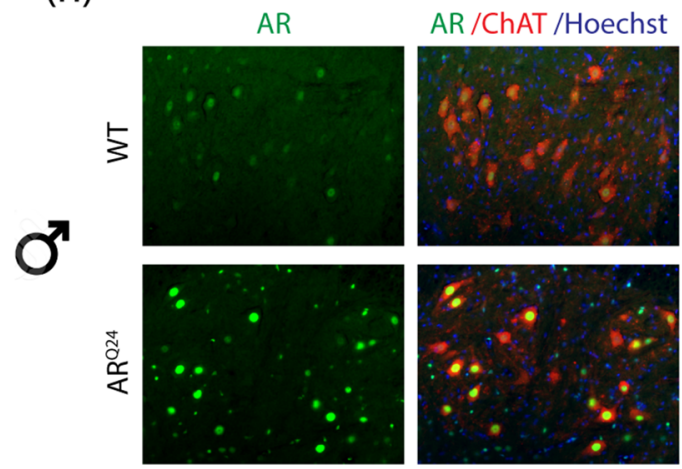

(i)

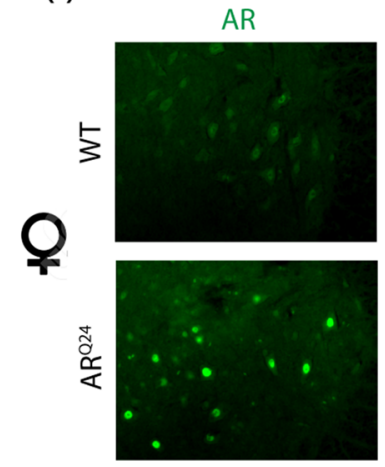

AR/ChAT /Hoechst
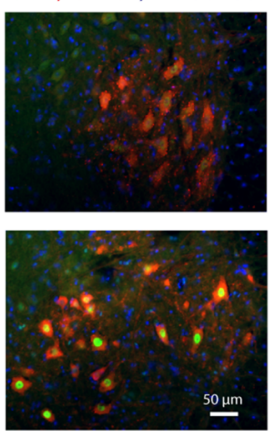
4Figure 1. Validation of AR expression in spinal cord and skeletal muscle of $n A R K O$ and $\mathrm{AR}^{\mathrm{Q} 24}$ mice. (a) AR transcript and (b) protein levels in nARKO spinal cord, compared to control genotypes. (c) AR transcript and (d) protein levels in nARKO gastrocnemius muscle, compared to control genotypes at 2 months age. Data represents mean \pm SEM, $\mathrm{n}=5$ mice per group. ${ }^{\star} \mathrm{P}<0.05$, ${ }^{* *} \mathrm{P}<0.001$, ${ }^{\star * * *} \mathrm{P}<0.0001$ by one-way ANOVA with Dunnett's multiple comparison test comparing all genotypes to WT. Full-length blots are presented in Supplementary Fig. 1a,b. (e) AR immunohistochemical staining in the ventral horn spinal cord of nARKO mice, compared with control genotypes, at 6 months age. Representative motor neurons indicated by white arrowheads. (f) AR protein expression in the lumbar spinal cord and (g) gastrocnemius muscle of male and female $\mathrm{AR}^{\mathrm{Q} 24}$ transgenic mice, relative to male WT levels at 3 months age. Data represents mean $\pm \mathrm{SEM}, \mathrm{n}=6$ mice per group. ${ }^{* *} \mathrm{P}<0.01,{ }^{* * *} \mathrm{P}<0.001,{ }^{* * * *} \mathrm{P}<0.0001$ by two-way ANOVA with Sidak's multiple comparisons test comparing genotype effect; ${ }^{*} \mathrm{P}<0.05$ by two-way ANOVA with Sidak's multiple comparisons test comparing sex effect. ${ }^{\dagger \dagger} \mathrm{P}<0.01,{ }^{\dagger \dagger} \mathrm{P}<0.001$ compared to WT male by unpaired $\mathrm{t}$-test. Full-length blots are presented in Supplementary Fig. S1c,d. (h) AR immunostaining in the lumbar spinal cord of male and (i) female WT and $\mathrm{AR}^{\mathrm{Q} 24}$ mice. Motor neurons are identified by positive ChAT staining.

flutamide, exacerbated muscle atrophy and induced an earlier disease onset in male SOD $1^{\mathrm{G} 93 \mathrm{~A}}$ mice ${ }^{20}$. Administration of the androgen, dihydrotestosterone (DHT), was neuroprotective in SOD ${ }^{\mathrm{G} 93 \mathrm{~A}}$ male mice ${ }^{21}$, while the anabolic steroid nandrolone was detrimental ${ }^{22}$. These studies highlight the differential actions and tissue-selectivity of biological and synthetic androgens. Lastly, evidence supports prenatal testosterone exposure potentially having an early impact on motor neuron vulnerability in later life ${ }^{9}$, whereas most of the studies conducted in SOD1 ${ }^{\mathrm{G} 93 \mathrm{~A}}$ mice manipulate AR signalling systems from adulthood at a time when disease onset occurs.

Here, we have used genetic manipulation of AR to study its impact throughout the lifespan of SOD $1^{\mathrm{G} 93 \mathrm{~A}}$ mice. Despite the compelling evidence for androgen influences in ALS, neither selective neural deletion nor global overexpression of AR modified the disease course of male SOD $1^{\mathrm{G} 93 \mathrm{~A}}$ mice. The Cre-LoxP conditional knockout strategy we employed to selectively delete AR from neurons and glia, used the Nestin-Cre (NesCre) mouse which inherently displays an altered metabolic phenotype. When crossed with SOD ${ }^{\mathrm{G} 93 \mathrm{~A}}$ mice, NesCre inadvertently delayed disease onset and extended survival, revealing that targeting hypermetabolism associated with ALS may be a more effective modulator of disease than sex hormones in this mouse model.

\section{Results}

Androgen receptor is efficiently and selectively deleted in spinal cord of $n A R K O$ mice. We first used a Cre-LoxP system in mice to obtain CNS-conditional deletion of AR. The NesCre transgenic expresses Cre-recombinase under the rat nestin promotor and enhancer, resulting in AR deletion from neuronal and glial precursor cells ${ }^{23}$. AR transcript was abolished by $96 \%$ of wild-type (WT) levels in neural AR knockout (nARKO) spinal cord (Fig. 1a) with a corresponding $78 \%$ depletion of AR protein (Fig. 1b, S1a). Gastrocnemius muscle revealed a 30\% reduction in AR transcript (Fig. 1c) with no change in AR protein level detected in nARKO mice (Fig. 1d, S1b). In lumbar spinal cord, nuclear AR was not detected in ventral horn motor neurons of nARKO mice which was comparable to the global knockout (gARKO) mouse (Fig. 1e). All 3 genotypes WT, AR flox and Nes-Cre expressed AR abundantly in nuclei of motor neurons in the spinal cord (Fig. 1e). Organ weight analysis showed consistently increased spleen $(0.061 \pm 0.007 \mathrm{~g}$ vs. $0.078 \pm 0.014 \mathrm{~g} ; P=0.035)$ and seminal vesicle $(0.12 \pm 0.035$ g vs. $0.24 \pm 0.053 \mathrm{~g} ; P<0.0001)$ weights in $n A R K O$ mice compared to NesCre controls, and reduced testis weights $(0.16 \pm 0.012 \mathrm{~g}$ vs. $0.12 \pm 0.009 \mathrm{~g} P=0.0002)$ from 2 months age onwards (Table S1). Increased seminal vesicle weights reflect elevated testosterone levels, a commonly observed concomitant of neuronal AR deletion models due to disruption of the hypothalamic-pituitary-gonadal (HPG) axis $^{24,25}$. The $\mathrm{AR}^{\text {flox }}$ mouse line, used in the current studies, was modified to remove a neomycin resistance cassette ${ }^{26}$ which interfered in AR gene function in several previous AR floxed models ${ }^{27,28}$. There is no known observable interference from loxP insertions in this mouse, confirmed by our assessment of long-term growth curves, major organ weights and AR quantification being indistinguishable from WT mice (Fig. 1a, 2a, S1, Table S1).

$A R$ is robustly overexpressed in motor neurons and skeletal muscle of $A R^{024}$ male and female mice. The $\mathrm{AR}^{\mathrm{Q} 24}$ mouse expresses 5 copies of the WT human AR transgene driven by the chicken $\beta$-actin promoter $^{29}$. In lumbar spinal cord, total AR protein levels were increased 4.4-fold in male $\mathrm{AR}^{\mathrm{Q} 24}$ mice, compared to WT controls, while in females this was slightly lower at threefold increase (Fig. If, S1c). In gastrocnemius muscle, total AR protein level was elevated 10.5-fold in male $\mathrm{AR}^{\mathrm{Q} 24}$ mice, compared to WT controls (Fig. 1g, $\mathrm{S} 1 \mathrm{~d})$. In $\mathrm{AR}^{\mathrm{Q} 24}$ females, $\mathrm{AR}$ was increased 8.8-fold compared to WT male mice. Male vs. female WT levels were not significantly different using two-way ANOVA analysis due to the dominating effect of the $\mathrm{AR}^{\mathrm{Q} 24}$ levels. When analysed separately, female WT mice had $40 \%$ less AR in lumbar spinal cord compared to males and $54 \%$ less AR in gastrocnemius, consistent with our previous study ${ }^{20}$. AR protein overexpression was reflected in ventral horn spinal cord immunohistochemistry (Fig. 1h,i), where nuclear AR staining was substantially greater in $\mathrm{ChAT}^{+}$motor neurons of $\mathrm{AR}^{\mathrm{Q} 24}$ male and female spinal cord, as well as appearing in the smaller nuclei of surrounding cell populations. Organ weights were comparable between male $\mathrm{AR}^{\mathrm{Q} 24}$ and $\mathrm{WT}$ controls, except for decreased skeletal muscle weight observed in $\mathrm{AR}^{\mathrm{Q} 24}$ mice (Table S2).

Neural AR deletion and global AR overexpression have a detrimental effect on survival of male mice. Male mice carrying the NesCre transgene displayed significant growth retardation over 24 months, compared to WT males, while $\mathrm{AR}^{\text {flox }}$ males displayed no overt impairments in growth and body weight (Fig. 2a). This has been reported previously in NesCre transgenic mice which have mild hypopituitarism and growth 
(a)

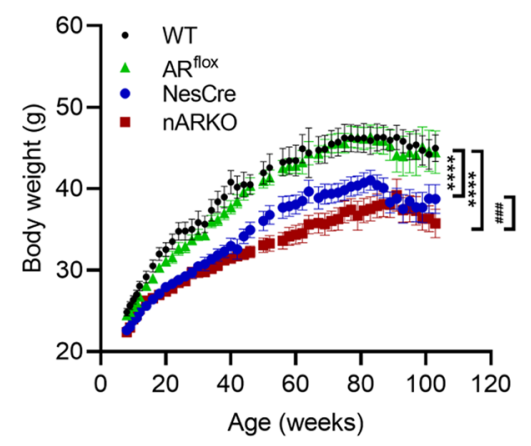

(c)

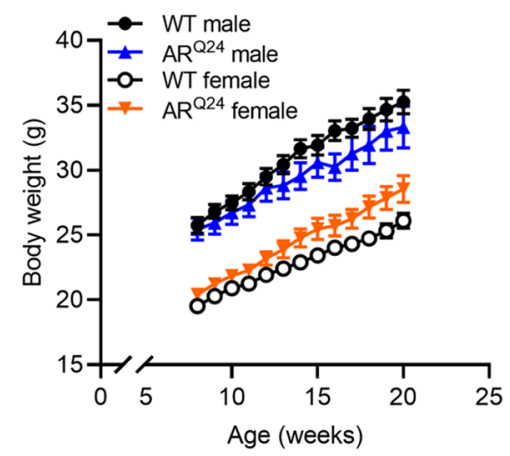

(b)

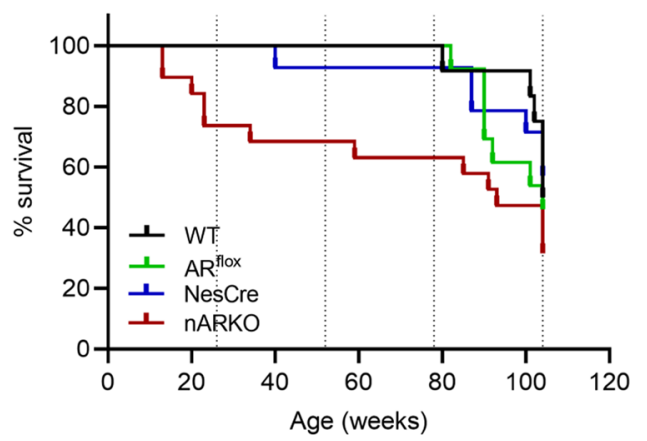

(d)

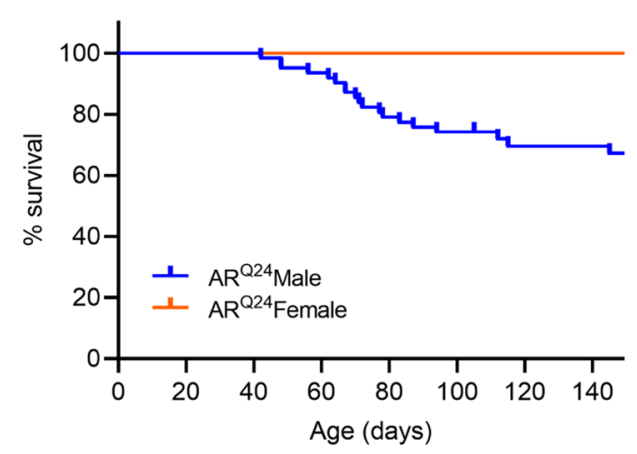

Figure 2. Impact of neural AR deletion and global AR overexpression on male mouse survival. (a) Body weight analysis of $\mathrm{AR}^{\text {flox }} \mathrm{x}$ NesCre cross mice over 24 months. Mean $\pm \mathrm{SEM}, \mathrm{n}=11-13$ mice per group. ${ }^{* * *} \mathrm{P}<0.0001$ vs WT; ${ }^{\# \# \# ~} \mathrm{P}<0.001$ vs NesCre by mixed-effects analysis with Tukey's multiple comparison test for main genotype effect. (b) Kaplan-Meier curves of $\mathrm{AR}^{\text {flox }} \mathrm{x}$ NesCre cross mouse survival over 24 months; $\mathrm{n}=12 \mathrm{WT}$; $=13$ $\mathrm{AR}^{\text {flox }} ; \mathrm{n}=14$ NesCre; $\mathrm{n}=10 \mathrm{nARKO}$. (c) Body weight analysis of $\mathrm{WT}$ and $\mathrm{AR}^{\mathrm{Q} 24}$ mice to P150. Mean $\pm \mathrm{SEM}$, $\mathrm{n}=12-14$ mice per group. (d) Kaplan-Meier curves of $\mathrm{AR}^{\mathrm{Q} 24}$ transgenic mouse survival over 150 days; $\mathrm{n}=62$ males.

hormone deficiency ${ }^{30}$. Body weight growth was further reduced in nARKO mice, compared to NesCre, revealing a requirement of $\mathrm{AR}$ for weight gain. Mice reached maximal weights of $49 \pm 5.1 \mathrm{~g}, 49 \pm 5.5 \mathrm{~g}, 43 \pm 4.8 \mathrm{~g}$ and $39 \pm 6.0 \mathrm{~g}$ for $\mathrm{WT}, \mathrm{AR}^{\text {flox }}$, NesCre and $\mathrm{nARKO}$ male mice, respectively. At 6 months of age, little difference in organ weights were observed between NesCre and nARKO mice, other than increased prostate weight $(0.08 \pm 0.01 \mathrm{~g}$ vs. $0.13 \pm 0.05 \mathrm{~g} ; P=0.0132)$ and previously mentioned spleen, seminal vesicle and testis differences (Table S1). Off-target AR deletion was evident in kidney, skeletal muscle and heart tissue in 6-month old nARKO mice (Fig S2), and elevated liver AR transcript and protein levels were apparent through secondary mechanisms with no genomic deletion of AR evident (Fig S2). Spontaneous deaths occurred in nARKO mice from 13 weeks ( 3 months) of age onward, with 8/10 mice showing no signs of ill-health prior to death (Fig. 2b). In this study cohort, 6/19 mice reached 24 months of age without appreciable weight loss, adverse events or evidence of abnormal gross pathology. Control genotypes began losing mice beyond 18 months of age, typically due to general poor health and weight decline. Mice reaching 24 months of age with no evidence of poor health included 6/12,6/13 and 8/14 mice for WT, $\mathrm{AR}^{\text {flox }}$ and NesCre groups, respectively (Fig. 2b). Aged nARKO mice showed significant enlargement of the prostate up to 6-fold, compared to NesCre controls $(0.108 \pm 0.016 \mathrm{~g}$ vs. $0.681 \pm 0.179 \mathrm{~g} ; P<0.0001$ for $\mathrm{nARKO}$ and NesCre mice, respectively. Table S1). No other differences in gross organ pathology were notable.

We analysed the effects of AR overexpression in male and female mice (Fig. 2c). A slight downward weight trend in $\mathrm{AR}^{\mathrm{Q} 24}$ males and upward trend in $\mathrm{AR}^{\mathrm{Q} 24}$ females was observed, compared to WT counterparts. This genotype effect was only found to be significant in females when analysed by repeated measures two-way ANOVA $\left(\mathrm{F}_{(1,22)}=5.056 ; P=0.0349\right)$. Unexpectedly, sudden deaths were observed in approximately one third of male $\mathrm{AR}^{\mathrm{Q} 24}$ mice by 150 days (Fig. 2d). These mice frequently showed a sudden rapid weight gain prior to death, indicative of fluid retention. Cardiac hypertrophy was evident on post-mortem inspection and was confirmed as the cause of death by external veterinary pathology. The occurrence of these deaths appear to coincide with rising circulating testosterone levels which we have previously reported in mice from P60-P150 age ${ }^{31}$. The heart weight of remaining healthy $\mathrm{AR}^{\mathrm{Q} 24}$ mice did not show a difference, compared to control WT mice, indicating incomplete penetrance of this phenotype in $\mathrm{AR}^{\mathrm{Q} 24}$ male mice (Supplementary material Fig S3a). Previously, this 
(a)

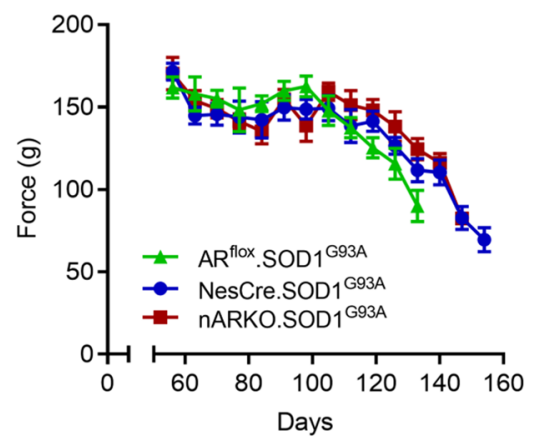

(b)

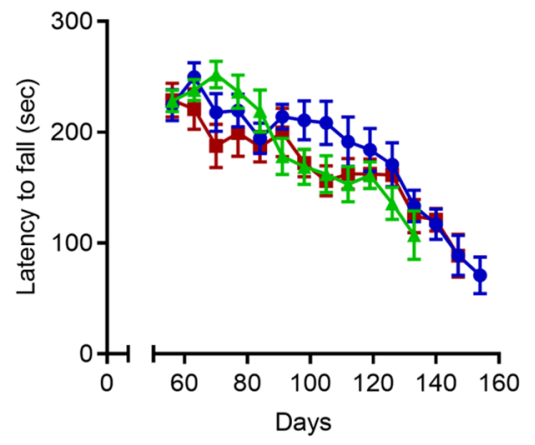

(c)

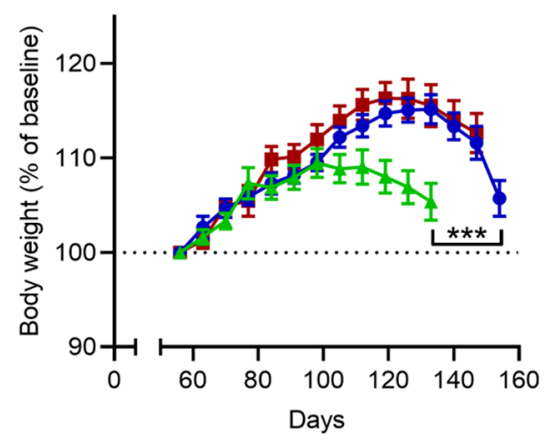

(d)

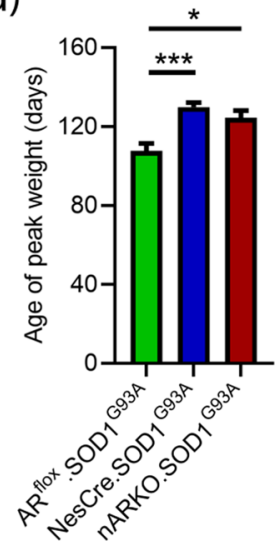

(e)

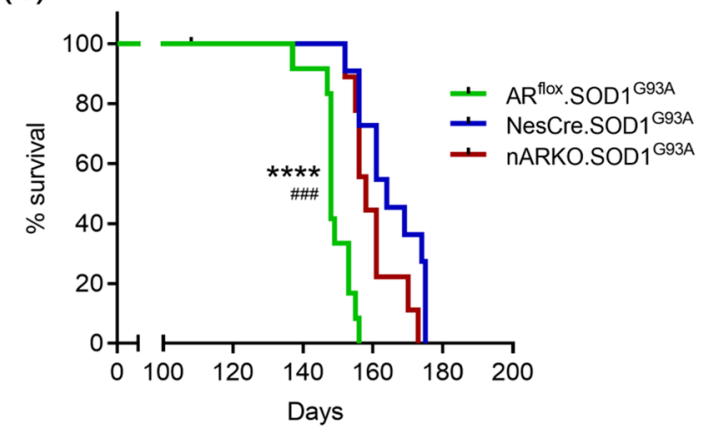

Figure 3. Neural deletion of AR does not alter disease course in SOD $1^{\mathrm{G} 93 \mathrm{~A}}$ male mice. Motor function assessment by (a) four limb grip strength and (b) rotarod performance. (c) Body weight analysis of $A^{\text {flox }} \mathrm{X}$ NesCre $x$ SOD $1^{\mathrm{G} 93 \mathrm{~A}}$ cross mice over disease course; ${ }^{* *} \mathrm{P}<0.001$ vs. NesCre:SOD $1^{\mathrm{G} 93 \mathrm{~A}}$ by two-way ANOVA with Tukey's multiple comparison test comparing main genotype effect. (d) Age in weeks when peak weight occurred; $\mathrm{P}<0.001$ by one-way ANOVA with Dunnett's multiple comparison test comparing all genotypes to NesCre:SOD1 ${ }^{\mathrm{G} 93 \mathrm{~A}}$. (e) Kaplan-Meier curves show reduced survival in $\mathrm{AR}^{\text {flox:SOD }}$ : $1^{\mathrm{G} 93 \mathrm{~A}}$ compared to NesCre:SOD $\left.1^{\mathrm{G} 93 \mathrm{~A}}{ }^{* * * *} \mathrm{P}<0.0001\right)$ and $\mathrm{nARKO}: \mathrm{SOD} 1^{\mathrm{G} 93 \mathrm{~A}}\left({ }^{\# \# \#} \mathrm{P}<0.001\right)$. All values presented as mean $\pm \mathrm{SEM}$; $\mathrm{n}=9-12$ mice per group.

genotype was backcrossed onto the C57BL/6 J genetic background and spontaneous deaths were not described in the phenotype ${ }^{29}$. Notably, the current B6D2 mixed background exhibits greater heart weight than C57BL/6 J counterparts ( $0.22 \pm 0.03 \mathrm{~g}$ vs. $0.12 \pm 0.01 \mathrm{~g}$; Fig S3), hence AR effects on cardiac phenotype may be exacerbated in mice on the B6D2 background. Likewise, nARKO heart weights were not different to NesCre controls throughout their lifespan (Fig S3b).

Neural deletion of AR does not alter disease course in SOD1 ${ }^{\text {G93A }}$ male mice. After establishing the effects of AR ablation in non-diseased mice, we next determined the impact of AR ablation in the CNS, on the phenotype of male transgenic SOD $1^{\mathrm{G} 93 \mathrm{~A}}$ mice. SOD $1^{\mathrm{G} 93 \mathrm{~A}}$ mice were generated with $\mathrm{nARKO}, \mathrm{AR}{ }^{\text {flox }}$ or NesCre transgenes. A comparison of limb muscle strength (Fig. 3a) and locomotor function (Fig. 3b) revealed no overt genotype differences. Body weight analysis showed an earlier symptomatic decline in the $\mathrm{AR}^{\text {flox }}$ :SOD ${ }^{\mathrm{G} 93 \mathrm{~A}}$ genotype from 105 days onwards $(P=0.0002$; Fig. 3c). Age of peak body weight was used to retrospectively assess disease onset (Fig. 3d). Onset was $108 \pm 13$ days in the $\mathrm{AR}^{\text {flox:SOD }} 1^{\mathrm{G} 93 \mathrm{~A}}$ group, in line with a previous recent assessment conducted on identical SOD $1^{\mathrm{G} 93 \mathrm{~A}}$ mice from within our laboratory, reporting onset at $110 \pm 20$ days using this method $^{20}$. NesCre:SOD $1^{\mathrm{G} 93 \mathrm{~A}}$ mice showed a delay in disease onset by 22 days, compared to AR ${ }^{\text {flox }}$ :SOD $1^{\mathrm{G} 93 \mathrm{~A}}$ $(P<0.0001)$ reaching peak body weight at $130 \pm 8$ days. nARKO:SOD ${ }^{\mathrm{G} 93 \mathrm{~A}}$ disease onset was slightly earlier than NesCre:SOD1 ${ }^{\mathrm{G} 93 \mathrm{~A}}$ mice at $124 \pm 11$ days, although this 6 -day difference was not statistically significant $(P=0.4623)$. NesCre:SOD $1^{\mathrm{G} 93 \mathrm{~A}}$ and $\mathrm{nARKO}: \mathrm{SOD} 1^{\mathrm{G} 93 \mathrm{~A}}$ mice showed a 16 and 10 day median survival extension, respectively, compared to $\mathrm{AR}^{\text {flox:SOD}} 1^{\mathrm{G} 93 \mathrm{~A}}$ (Fig. 3e). nARKO:SOD $1^{\mathrm{G} 93 \mathrm{~A}}$ mice showed a modest reduction in median survival by 6 days, compared to NesCre:SOD ${ }^{\mathrm{G} 93 \mathrm{~A}}$ which approached statistical significance $(P=0.07)$ by the log-rank test. Taken together, the NesCre phenotype appears to be driving the survival extension in SOD $1^{\mathrm{G} 93 \mathrm{~A}}$ male mice.

Overexpression of AR does not influence disease parameters in SOD $1^{\text {G93A }}$ mice. With evidence that neither deletion of AR from neurons, nor peripheral AR antagonism ${ }^{20}$ are capable of modifying disease outcome in $\mathrm{SOD} 1^{\mathrm{G} 93 \mathrm{~A}}$ mice we turned to an overexpression model. The effects of global AR overexpression were 


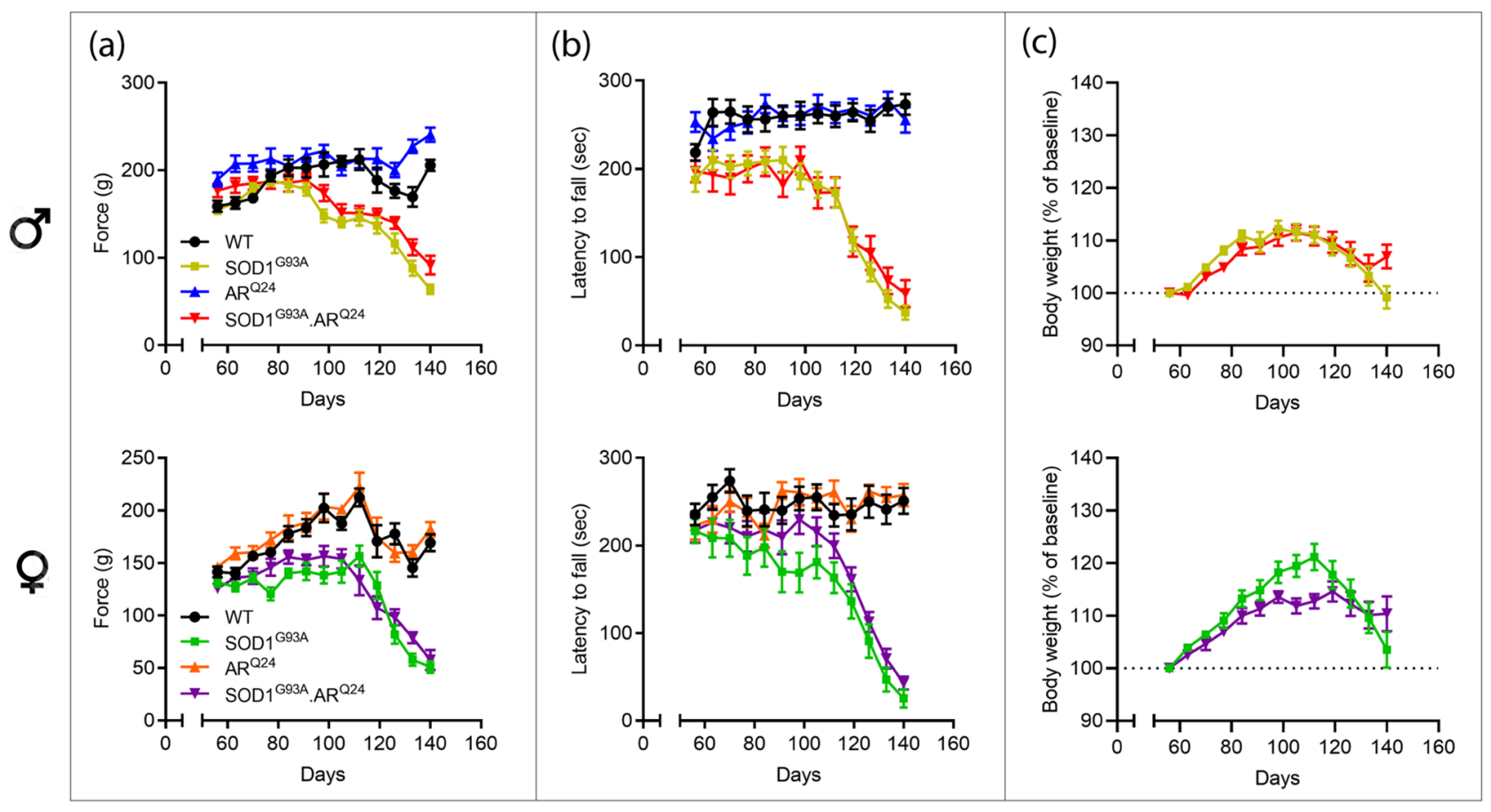

(d)

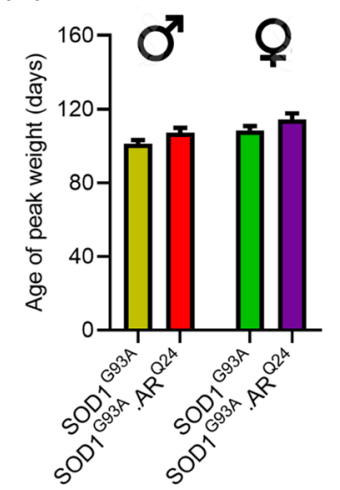

(e)

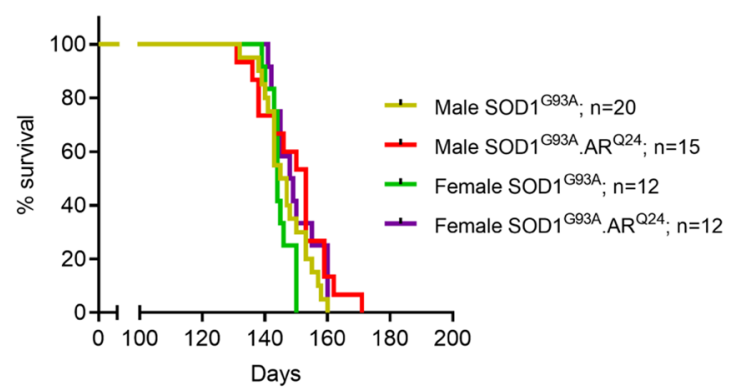

Figure 4. Global overexpression of AR does not influence disease progression and survival in SOD1 ${ }^{\mathrm{G} 93 \mathrm{~A}}$ mice. Motor function assessment by (a) four limb grip strength and (b) rotarod performance and (c) body weight analysis of $\mathrm{AR}^{\mathrm{Q} 24} \mathrm{x}$ SOD1 ${ }^{\mathrm{G} 93 \mathrm{~A}}$ cross male and female mice over disease course. (d) Age in weeks when peak weight occurred in males and female. (e) Kaplan-Meier curves showing comparable survival in SOD1 ${ }^{\mathrm{G} 93 \mathrm{~A}}: \mathrm{AR}^{\mathrm{Q} 24}$ mice compared to SOD1 ${ }^{\mathrm{G} 93 \mathrm{~A}}$ mice. All values presented as mean \pm SEM; $\mathrm{n}=12-20$ mice per group.

evaluated in $\mathrm{SOD} 1^{\mathrm{G} 93 \mathrm{~A}}$ mice. SOD $1^{\mathrm{G} 93 \mathrm{~A}}$ mice were crossed with $\mathrm{AR}^{\mathrm{Q} 24}$ mice, giving rise to $\mathrm{WT}$, SOD1 ${ }^{\mathrm{G} 93 \mathrm{~A}}, \mathrm{AR}^{\mathrm{Q} 24}$ and SOD1 ${ }^{\mathrm{G} 93 \mathrm{~A}}: \mathrm{AR}^{\mathrm{Q} 24}$ genotypes. Muscle strength showed comparable decline in SOD1 ${ }^{\mathrm{G} 93 \mathrm{~A}}$ and SOD $1^{\mathrm{G} 93 \mathrm{~A}}: \mathrm{AR}^{\mathrm{Q} 24}$ mice with consistent performance maintained in aged-matched non-disease counterparts, $\mathrm{AR}^{\mathrm{Q} 24}$ and WT mice (Fig. 4a). In SOD $1^{\mathrm{G} 93 \mathrm{~A}}$ male mice, the onset of decline in grip strength was $89 \pm 9$ days compared to $103 \pm 12$ days in female mice $(P=0.0006$ by unpaired t-test, Fig S4a). AR overexpression did not have a significant effect on the onset of decline in grip strength in SOD1 $1^{\mathrm{G} 93 \mathrm{~A}}$ mice, with onset occurring at $95 \pm 10$ days and $102 \pm 11$ days in SOD1 ${ }^{\mathrm{G} 93 \mathrm{~A}}: \mathrm{AR}^{\mathrm{Q} 24}$ male and female mice, respectively. Similar trends were observed in locomotor performance (Fig. 4b) with the onset of decline in function occurring at $102 \pm 10$ days compared to $110 \pm 7$ days in male and female $\mathrm{SOD} 1^{\mathrm{G} 93 \mathrm{~A}}$ mice, respectively $(\mathrm{P}=0.0221$ by unpaired t-test, Fig $\mathrm{S} 4 \mathrm{~b})$. Again, AR overexpression did not have an effect on disease onset determined by locomotor performance, occurring at $107 \pm 9$ days and $106 \pm 9$ days in $\mathrm{SOD} 1^{\mathrm{G} 93 \mathrm{~A}}: \mathrm{AR}^{\mathrm{Q} 24}$ male and female mice, respectively. Comparable weight declines were apparent between $\mathrm{SOD} 1^{\mathrm{G} 93 \mathrm{~A}}$ and $\mathrm{SOD} 1^{\mathrm{G} 93 \mathrm{~A}}: \mathrm{AR}^{\mathrm{Q} 24}$ genotypes (Fig. 4c). Age of peak body weight showed a significant effect of sex $\left(\mathrm{F}_{(1,56)}=7.82 ; P=0.0071\right)$ and genotype $\left(\mathrm{F}_{(1,56)}=5.24 ; P=0.0258\right)$ on disease onset when analysed by two-way ANOVA (Fig. 4d). Multiple comparisons did not reveal significant intergroup differences. Separate analysis of male vs. female SOD $1^{\mathrm{G} 93 \mathrm{~A}}$ mice again revealed males had a significantly earlier disease onset compared to female mice $(\mathrm{P}=0.0271$ by unpaired t-test, Fig $\mathrm{S} 4 \mathrm{c})$, showing a consistent trend across multiple methods of determining disease onset in SOD $1^{\mathrm{G} 93 \mathrm{~A}}$ mice. The median lifespan of male SOD1 ${ }^{\mathrm{G} 93 \mathrm{~A}}$ mice (146 days) was comparable to SOD1 ${ }^{\mathrm{G} 93 \mathrm{~A}}: \mathrm{AR}^{\mathrm{Q} 24}$ mice (153 days) $(P=0.1494)$. Likewise, in females, no survival differences were apparent, with median survival of 144 vs. 149 days for SOD $1^{\mathrm{G} 93 \mathrm{~A}}$ and $\mathrm{SOD} 1^{\mathrm{G} 93 \mathrm{~A}}: \mathrm{AR}^{\mathrm{Q} 24}$ mice, respectively $(P=0.0810$; Fig. 4e). 
(a)

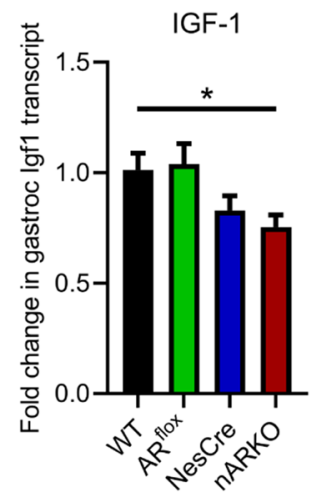

(b)

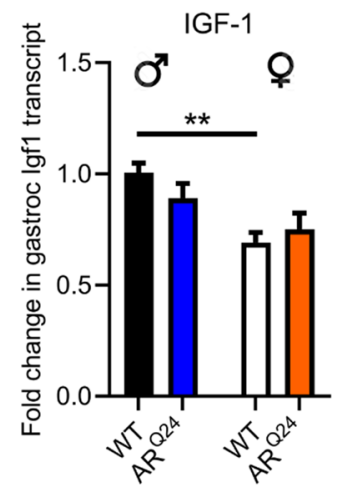

Figure 5. AR expression levels do not drive an alteration in skeletal muscle IGF-1 transcript. (a) IGF-1 transcript levels in gastrocnemius muscle of $\mathrm{AR}^{\text {flox }} \mathrm{x}$ NesCre male mice at 2 months age. Data represents mean \pm SEM, $\mathrm{n}=5$ mice per group. ${ }^{\star} \mathrm{P}<0.05$ by one-way ANOVA with Dunnett's multiple comparison test comparing all genotypes to WT. (b) IGF-1 transcript levels in gastrocnemius muscle of male and female $\mathrm{AR}^{\mathrm{Q} 24}$ mice compared to WT at 3 months age. Data represents mean \pm SEM, $\mathrm{n}=6$ mice per group. ${ }^{* *} \mathrm{P}<0.01$ by twoway ANOVA with Sidak's multiple comparisons test comparing sex effect.

Changes in AR expression do not drive an alteration in skeletal muscle IGF-1 transcript. Insulin-like growth factor 1 (IGF-1) is a known transcriptional target of skeletal muscle $\mathrm{AR}^{32}$ and mediates local trophic effects ${ }^{33}$ and neuroprotective actions in motor neurons ${ }^{34}$. IGF-1 expression in muscle was not altered in $\mathrm{AR}^{\text {flox }}$ mice, whereas it appears to be downregulated in the NesCre mice by $17 \%$ compared to WT (Fig. 5a). While nARKO mice were significantly downregulated by $25 \%$ compared to WT males, there is no difference when compared to NesCre controls (Fig. 5a). Interestingly, there was no effect of overexpressing AR on muscle IGF-1 expression (Fig. 5b). A sex effect is observed $\left(\mathrm{F}_{(1,56)}=5.24 ; P=0.0258\right)$ with female WT mice showing a $30 \%$ reduction in IGF- 1 transcript compared to WT males, indicating that androgen levels rather than AR levels, dictate regulation of IGF-1.

\section{Discussion}

We have explored the impact of genetic manipulation of AR on motor performance, growth and survival in healthy and diseased mice. To selectively delete AR within the CNS, we crossed the floxed AR mouse with the NesCre mouse which expresses Cre-recombinase in neural progenitor cells. Neural AR deletion did not show significant impacts upon disease progression and survival of SOD1 ${ }^{\mathrm{G} 93 \mathrm{~A}}$ transgenic mice compared to NesCre controls. The introduction of the NesCre transgene to SOD $1^{\mathrm{G} 93 \mathrm{~A}}$ mice profoundly increased survival by 16 days, compared to those carrying the phenotypic benign $\mathrm{AR}^{\text {flox }}$ transgene. Overexpression of AR did not modify disease progression and survival in SOD ${ }^{\mathrm{G} 93 \mathrm{~A}}$ male or female mice. However, both AR deletion and overexpression models negatively influenced the survival of non-diseased male mice with incomplete penetrance.

The widespread presence of AR and systemic testosterone action throughout the body make it difficult to isolate tissue-specific impacts of AR signalling. Deletion of AR from the CNS results in disruptions to the HPG axis regulating testosterone release, resulting in elevated circulating testosterone levels ${ }^{25,35}$. In a calcium/calmodulindependent protein kinase II $(\mathrm{CaMKII} \alpha)$-iCre driven ARKO mouse, testosterone levels were increased 2 -fold and seminal vesicle weight increased 4 -fold ${ }^{25}$. In nARKO mice, 2 to 4 -fold elevations in circulating testosterone have been reported ${ }^{24,35}$, reflecting the $\sim 2$-fold increased seminal vesicle weight in our study. The NesCre driver line also reportedly has activity outside of the intended target, causing further potential confounds ${ }^{36,37}$. Therefore, the implications of altered AR signalling in the periphery of nARKO mice cannot be discounted. In gastrocnemius muscle, we report no net change to AR protein level in nARKO mice, despite a 30\% reduction in AR transcript level. This could be due to altered local androgen levels affecting AR protein turnover ${ }^{31}$. In myocyte-specific $\mathrm{KO}$ mice, AR was not found to contribute to androgen-mediated hypertrophy in gastrocnemius or other limb muscles, although it negatively impacted muscle strength ${ }^{38,39}$. Conversely, we have previously reported that systemic administration of the AR competitive antagonist, flutamide, promoted muscle atrophy and enhanced disease onset, without altering survival in SOD $1^{\mathrm{G} 93 \mathrm{~A}}$ male mice ${ }^{20}$. Interestingly, restricted overexpression of WT AR in muscle had a detrimental effect, with mice developing a neurodegenerative phenotype similar to SBMA models ${ }^{40}$. Our global overexpression model, which expresses human WT AR, decreased gastrocnemius muscle weight, mildly reduced body weight in non-disease males, and had no influence on disease progression in SOD $1^{\mathrm{G} 93 \mathrm{~A}}$ mice. The reason for the discrepancies observed between these overexpressing models could be the different promotors used to drive transgene expression. In the skeletal muscle-specific model, $\mathrm{AR}^{\mathrm{Q} 22}$ expression was driven by $a$-actin which is far more abundant in muscle compared to $\beta$-actin ${ }^{41}$, used to drive global AR expression in the current study. It is possible that the level of AR in muscle in the former model prompted a toxic gain of function. In models of SBMA it has been shown that expression of the polyglutamine expanded $\mathrm{AR}$ in muscle alone, is capable of driving neurological components of the disease. Males have an earlier disease 
onset in both mouse models and clinical ALS, with denervation and muscle atrophy among the earliest presymptomatic pathologies of the disease ${ }^{42}$. Further exploration of the role of skeletal muscle AR in driving disease onset in ALS models is warranted.

The perturbation of AR signalling outside of the CNS in these models is likely responsible for the negative survival effects observed in non-disease models. This is especially relevant for the $\mathrm{AR}^{\mathrm{Q} 24}$ overexpression model where sudden death appeared to be the result of cardiac hypertrophy. The role of androgens in human cardiovascular disease is contradictory. The risk of cardiovascular disease is higher in males than females, which could indicate a negative impact of AR signalling. Likewise, androgens acting via AR impair recovery of cardiac function after ischemia-reperfusion injury ${ }^{43}$ and promote chronic kidney disease ${ }^{44}$. Conversely, lower testosterone levels in ageing males correlates with greater cardiovascular disease mortality ${ }^{45}$. In global ARKO models, mice exhibit increased atherosclerosis, higher circulating cholesterol and increased development of cardiac fibrosis, as reviewed by Chang and colleagues ${ }^{46}$. In $\mathrm{nARKO}$ mice, we observed genetic deletion of AR within both kidney and heart tissue. This age-dependence and contradictory role of AR in cardiovascular disease is reflected in our survival data in AR genetic models. Deaths in nARKO mice, typically occurred beyond 5 months of age; in $\mathrm{AR}^{\mathrm{Q} 24}$ mice this occurred much earlier coinciding with rising circulating testosterone levels.

We have previously reported that AR is depleted in the lumbar spinal cords of male SOD1 ${ }^{\mathrm{G} 93 \mathrm{~A}}$ mice $^{31}$. In light of this finding, further abolishment of AR signalling, through AR deletion, may have limited impact on disease course and survival. We did observe a mild 6-day reduction in median survival of nARKO:SOD1 ${ }^{\mathrm{G} 93 \mathrm{~A}}$ males, compared to NesCre:SOD1 ${ }^{\mathrm{G} 93 \mathrm{~A}}$ males, although not significant. A higher prenatal testosterone exposure associates with ALS $^{9}$. This contrasts to evidence that early postnatal testosterone administration is neuroprotective against cortical injury in adult rodents ${ }^{47}$. In NesCre mice, Cre-LoxP recombination is reported to have occurred throughout the CNS by E15.5 ${ }^{36}$. This is prior to the first testosterone surge, occurring between E17-19 in rodents ${ }^{48}$. Therefore, we anticipate that the direct effects of early prenatal testosterone exposure on neurons is sufficiently abolished in $\mathrm{nARKO}: \mathrm{SOD} 1^{\mathrm{G} 93 \mathrm{~A}}$ mice and has minimal impact on adult disease course. The levels of testosterone in $\mathrm{AR}^{\mathrm{Q} 24}$ mice have not been reported. No change in testosterone levels were evident in a CMVpromoter driven AR overexpression model ${ }^{49}$. It therefore seems unlikely that dysregulation in testosterone production and reduced AR signalling is responsible for the lack of effect observed in the SOD1 ${ }^{\mathrm{G} 93 \mathrm{~A}}: \mathrm{AR}^{\mathrm{Q} 24}$ model. Quantification of skeletal muscle IGF-1 transcript, a known AR transcriptional target, was not altered by AR overexpression. A lower level of the transcript was observed in female WT mice, implicating local androgens as driving transcript levels independent of AR level. This is supported by evidence that exogenous administration of DHT to male SOD1 ${ }^{\mathrm{G} 93 \mathrm{~A}}$ mice, significantly upregulated IGF-1 transcript in tibialis anterior muscle ${ }^{21}$.

In the current study we did not observe AR-mediated alteration in disease onset or outcome in SOD1 ${ }^{\mathrm{G} 93 \mathrm{~A}}$ mice. While we cannot rule out that model limitations confounded the ability to detect an underlying role for $\mathrm{AR}$, it is also possible that other factors are mediating the sex-specific differences in ALS. Estrogen receptors (ER) are abundantly expressed by motor neurons and all glial cell populations in the lumbar spinal cord of SOD $1^{\mathrm{G} 93 \mathrm{~A}}$ mice $^{31}$. Exogenous estradiol has potent anti-inflammatory actions and provides neuroprotection to motor neurons when administered to male SOD ${ }^{\mathrm{G} 93 \mathrm{~A}}$ mice $^{50}$. Exogenous progesterone, stimulated autophagy in the spinal cord of male SOD $1^{\mathrm{G} 93 \mathrm{~A}}$ mice, delaying disease onset and extending survival ${ }^{51}$. Ovariectomy in female SOD1 ${ }^{\mathrm{G} 93 \mathrm{~A}}$ mice did not impact disease onset, but accelerated disease progression ${ }^{52}$. Together, these studies present a strong case for estrogens and progesterone having multiple neuroprotective and disease modifying actions in SOD1 ${ }^{\mathrm{G} 93 \mathrm{~A}}$ mice. Alternatively, it is possible that sex chromosome effects could be mediating sex differences in ALS, independently of gonadal hormones ${ }^{53}$. For example, in multiple sclerosis and autoimmune disease, differential methylation of the X-chromosome gene, Foxp3, has been identified in T lymphocytes; possibly resulting from X-chromosome imprinting ${ }^{54,55}$. In Parkinson's disease, the expression of Y chromosome gene, SRY, is upregulated and promotes nigrostriatal degeneration ${ }^{56}$. This may contribute to the male bias of the disease.

The NesCre mouse has been described as having a metabolic phenotype ${ }^{37}$ caused by the ectopic expression of the human growth hormone gene in the hypothalamus ${ }^{57}$. This causes a decrease in growth hormone regulating hormone (GHRH) release by mouse hypothalamic neurosecretory neurons. In turn this leads to a $70-80 \%$ reduction in growth hormone $(\mathrm{GH})$ release by the anterior pituitary ${ }^{30}$. Likewise, the pituitary hormones prolactin (PRLH) and thyroid stimulating hormone (TSH) were similarly decreased. GH is responsible for promoting growth, hence, the observed impairment in weight gain in the NesCre mice. GH operates to stimulate lipid and carbohydrate metabolism acting primarily on the adipose/fat tissue and liver. We have summarised the disrupted energy metabolism effects described for NesCre transgenic mice in Fig S5. Notably, a 50\% reduction in liver IGF-1 transcript, a major target of GH action, was observed ${ }^{57}$. Most of these actions, including increased leptin production, increased insulin sensitivity and higher adiposity ${ }^{58}$, act to promote energy storage. Additionally, the reduced TSH production by the pituitary and resulting thyroid hormone deficiency would be expected to contribute to a hypometabolic state ${ }^{59}$ in the NesCre mouse.

Hypermetabolism, defined by increased resting energy expenditure, is a well described early phenomenon in ALS patients. It does not appear to correlate with age, sex or $\mathrm{BMI}^{60}$, although clearly associates with poor prognosis $^{61}$. Likewise, hypermetabolism is also an early pre-symptomatic feature of disease in SOD1 ${ }^{\mathrm{G} 93 \mathrm{~A}}$ mice $^{62-65}$. The mechanisms leading to hypermetabolism in the SOD1 ${ }^{\mathrm{G} 93 \mathrm{~A}}$ mice appear to be highly complex and have only recently begun to be unravelled. A GH deficiency and decrease in IGF-1 signalling were evident in advanced symptomatic SOD $1^{\mathrm{G} 93 \mathrm{~A}}$, reflecting clinical $\mathrm{ALS}^{62}$. Further studies revealed GH secretions fluctuate with disease course showing an elevation coinciding with onset of disease ${ }^{65}$. The authors suggested this to be a response to denervation, in an attempt to stimulate muscle repair through IGF-1 upregulation. We show decreased IGF-1 transcript in skeletal muscle of NesCre mice, therefore, this pathway unlikely presents the mechanism of neuroprotection when crossed with $\mathrm{SOD} 1^{\mathrm{G} 93 \mathrm{~A}}$ mice. Skeletal muscle plays a major role in determining systemic metabolic rate ${ }^{66}$ and seems a likely contributor to metabolic dysfunction in ALS. In SOD1 ${ }^{\mathrm{G} 93 \mathrm{~A}}$ mice an increase in fatty acid oxidation occurs in muscle, reflecting a switch toward the used of lipids as a primary fuel source 
in peripheral tissues ${ }^{64,67}$. In NesCre mice, increased lipid uptake and storage occurs and may counteract the dysregulation in energy source occurring in SOD $1^{\mathrm{G} 93 \mathrm{~A}}$ mice (Fig S5). This is supported by evidence of lifespan extension in SOD $1{ }^{\mathrm{G} 93 \mathrm{~A}}$ mice when crossed with a transgenic harbouring a Dynein Cra mutation; the latter causing defective lipolysis and increased lipid stores ${ }^{68}$. The resulting double transgenic mice showed an increased adiposity and restoration in the use of carbohydrate energy sources. More recently, impaired glucose homeostasis was shown in symptomatic SOD $1^{\mathrm{G} 93 \mathrm{~A}}$ mice $^{69}$. This was characterised by two major defects: increased glucose uptake, independent of altered insulin sensitivity; and impaired glucagon signalling, the pancreatic hormone stimulating conversion of liver glycogen to glucose. NesCre mice have been shown to have dysregulated insulin and glucose sensitivity, presenting another potential mechanism to counter SOD1 ${ }^{\mathrm{G} 93 \mathrm{~A}}$ hypermetabolism.

In conclusion, we demonstrate here that genetic perturbations to AR levels in mice can have detrimental impacts on male mice, although, these do not exacerbate or alter the disease course in SOD1 ${ }^{\mathrm{G} 93 \mathrm{~A}}$ mice. Furthermore, AR manipulation alone may be insufficient to modulate disease with circulating and local tissue hormone levels likely to be the driving force behind sex differences in ALS. Finally, the altered metabolism in NesCre mice has inadvertently provided striking evidence that combating early hypermetabolism in SOD ${ }^{\mathrm{G} 93 \mathrm{~A}}$ is likely a key target in modulation of ALS progression.

\section{Methods}

Animals. All experiments on mice were conducted in accordance with the Australian National Health and Medical Research Council published Code of Practice and approved by the Florey Institute of Neuroscience and Mental Health Animal Ethics Committee (approval numbers 16-001-FINMH and 17-074-FINMH). The study was carried out in compliance with the ARRIVE guidelines. Transgenic SOD1 ${ }^{\mathrm{G} 93 \mathrm{~A}}$ mice (B6.Cg$\mathrm{Tg}\left(\mathrm{SOD} 1^{\star} \mathrm{G} 93 \mathrm{~A}\right) 1 \mathrm{Gur} / \mathrm{J}$ line; stock number 004435), $\mathrm{AR}^{\text {flox }}$ mice $^{26}$ (B6.129S1-Ar ${ }^{\mathrm{tm} 2.1 \mathrm{Reb} / \mathrm{J} \text { line, stock number }}$ $018450)$ and Nestin-Cre (NesCre) mice ${ }^{23}$ (B6.Cg-Tg(Nes-cre) $1 \mathrm{Kln} / \mathrm{J}$ line, stock number 003771) were purchased from the Jackson Laboratory (Bar Harbor, ME, USA) were maintained on a C57BL/6J background. Transgenic $\mathrm{AR}^{\mathrm{Q} 24}$ mice ${ }^{29}\left(\mathrm{~B} 6 \mathrm{D} 2-\mathrm{Tg}\left(\mathrm{CAG}-\mathrm{AR}^{\star} 24 \mathrm{Q}\right) 5-5 \mathrm{Sobu}\right.$; stock number RBRC00827) were purchased from RIKEN BioResource Centre and maintained on a B6D2 background.

To generate conditional neural ARKO mice, heterozygous female $\mathrm{AR}^{\mathrm{f} / \mathrm{wt}}$ mice were crossed with male $\mathrm{NesCre}^{+/-}$to generate four litter-matched male genotypes; non-transgenic WT, $\mathrm{AR}^{\mathrm{fl}}, \mathrm{NesCre}^{+/-}$and $\mathrm{AR}^{\mathrm{fl}}: \mathrm{NesCre}^{+/-}$ (nARKO). To generate constitutive ARKO mice for negative control tissue, $\mathrm{AR}^{\mathrm{f} / \mathrm{wt}}: \mathrm{NesCre} \mathrm{C}^{+/}$- double heterozygous transgenic females were bred with male mice giving rise to AR null males (gARKO) through germline recombination, as previously described ${ }^{70}$. Given the high frequency of germline recombination in female $\mathrm{AR}^{\mathrm{f} / \mathrm{wt}}: \mathrm{NesCre}^{+/-}$ breeders $^{70}$ it was not viable to pair with SOD $1^{\mathrm{G} 93 \mathrm{~A}}$ male breeders. Male SOD1 ${ }^{\mathrm{G} 93 \mathrm{~A}}$ mice were crossed with female $\mathrm{NesCre}^{+/-}$to generate male SOD ${ }^{\mathrm{G} 93 \mathrm{~A}}: \mathrm{NesCre}^{+/-}$transgenic mice. Due to SOD ${ }^{\mathrm{G} 93 \mathrm{~A}}$ and NesCre transgenes being located on chromosome 12, in male SOD $1^{\mathrm{G} 93 \mathrm{~A}}: \mathrm{NesCre}^{+/-}$, these two transgenes were segregated during meiosis and not inherited together in $\mathrm{F} 1$ progeny. We acquired a unique transgenic male SOD ${ }^{\mathrm{G} 93 \mathrm{~A}}: \mathrm{NesCre}^{+/-}$through chance breeding whereby the SOD $1^{\mathrm{G} 93 \mathrm{~A}}$ and $\mathrm{NesCre}{ }^{+/-}$became linked to chromosome 12 through homologous recombination. These mice were crossed with $\mathrm{AR}^{\mathrm{fl} / \mathrm{wt}}$ heterozygous females to produce $\mathrm{AR}^{\mathrm{wt}}: \mathrm{NesCre}{ }^{+/-}: \mathrm{SOD} 1^{\mathrm{G} 93 \mathrm{~A}}$ (NesCre:SOD $1^{\mathrm{G} 93 \mathrm{~A}}$ ) and $\mathrm{AR}^{\mathrm{fl}}$ : NesCre ${ }^{+/-}: \mathrm{SOD}^{\mathrm{G} 93 \mathrm{~A}}$ triple transgenic male (nARKO:SOD1 ${ }^{\mathrm{G} 93 \mathrm{~A}}$ ) littermates. A parallel breeding strategy was set up where $S O D 1^{\mathrm{G} 93 \mathrm{~A}}$ mice were crossed with $\mathrm{AR}^{\mathrm{f} / \mathrm{wt}}$ heterozygous females to generate $\mathrm{AR}^{\mathrm{fl}}: \mathrm{SOD} 1^{\mathrm{G} 93 \mathrm{~A}}$ males $\left(\mathrm{AR}^{\text {flox }}: \mathrm{SOD} 1^{\mathrm{G} 93 \mathrm{~A}}\right)$.

To generate AR overexpressing SOD $1^{\mathrm{G} 93 \mathrm{~A}}$ mice, female $\mathrm{AR}^{\mathrm{Q} 24}$ heterozygous mice were crossed with male SOD $1^{\mathrm{G} 93 \mathrm{~A}}$ to generate four litter-matched male genotypes; non-transgenic WT, SOD $1^{\mathrm{G} 93 \mathrm{~A}}, \mathrm{AR}^{\mathrm{Q} 24}$ and $\mathrm{SOD} 1^{\mathrm{G} 93 \mathrm{~A}}: \mathrm{AR}^{\mathrm{Q} 24}$. The mice were a mixed isogenic F1 background.

Animals were group-housed under standard $12 \mathrm{~h}$ light-dark conditions with access to standard rodent chow and water. At 2, 3 or 6 months of age, animals were killed by lethal dose of sodium pentobarbitone $(100 \mathrm{mg} / \mathrm{kg}$, i.p.) and organs collected, weighed and snap frozen in dry-ice. For immunohistochemistry, mice were cardiac perfused with $0.1 \mathrm{M}$ PBS followed by $4 \%$ paraformaldehyde, sucrose cryoprotected and snap freezing in isopentane as previously described ${ }^{31}$.

RT-qPCR. Spinal cord and gastrocnemius muscle were prepared and RNA extractions performed as previously described ${ }^{20,31}$. Brain, liver, kidney, gastrocnemius and heart tissue from NesCre and nARKO mice were mechanically pulverised using liquid nitrogen prior to processing for DNA, RNA and protein extraction. Genomic DNA (gDNA) was extracted from tissue samples overnight using PureLink Genomic DNA Mini Kit (Invitrogen) according to manufacturer's protocol. Primer sequences for gDNA were: $A r^{e x 1}$ forward $5^{\prime}$ - AAG CAG GTA GCT CTG GGA CA -3', Ar ${ }^{e x 1}$ reverse 5'- GAG CCA GCG GAA AGT TGT AG -3'; and internal control DAG1 forward 5' - CCA AGG AGC AGA TCA TAG GGC -3', DAG1 reverse 5'- AGA GCA TTG GAG AAG GCA GG -3'. For RNA extraction tissue was homogenised in QIAzol Lysis Reagent (Qiagen, Cat\# 79306) using the TissueLyserLT (Qiagen) for $5 \mathrm{~min}$ at $50 \mathrm{~Hz}$ and RNA containing phase isolated using chloroform prior to further purification using RNeasy Mini Kit following manufacturer's protocol. Primer sequences for RNA were: Ar forward 5'- GTG AAA TGG GAC CTT GGA TG -3', Ar reverse 5'- GCC AGA AGC TTC ATC TCC AC -3'; Igf1 forward 5'- TGG ATG CTC TTC AGT TCG TG -3', Igf1 reverse 5'- GCA ACA CTC ATC CAC AAT GC -3'; and internal control Hprt1 forward 5' - GAT CAG TCA ACG GGG GAC AT -3', Hprt1 reverse 5'- CAT TTT GGG GCT GTA CTG CTT -3'. RT-qPCR was performed as previously described ${ }^{20}$ and samples analysed in triplicate with Ct values normalized to the housekeeping gene. Fold change between WT control and transgenic groups was determined using the $2^{-\Delta \Delta \mathrm{Ct}}$ method.

Western blotting. Spinal cord and gastrocnemius muscle were prepared and protein extractions performed as previously described ${ }^{20,31}$. Brain, liver, kidney and heart tissue was homogenised by sonication ( $50 \%$ ampli- 
tude pulses applied over 10-15 s) in ice-cold RIPA buffer (50 mM Tris-Cl, pH 7.4, $150 \mathrm{mM} \mathrm{NaCl,} 0.1 \%$ SDS, $1 \%$ sodium deoxycholate and $1 \%$ Triton-X 100) containing protease and phosphatase inhibitor cocktail tablets. Protein lysates were denatured and electrophoresed through 4-15\% Criterion TGX Stain-Free gels (Bio-Rad Laboratories, NSW, Australia) or 4-20\% Mini-PROTEAN TGX Stain-Free gels (for brain, liver, kidney and heart supernatants) and transferred onto PVDF membrane using a Trans-Blot Turbo Transfer System (Bio-Rad) as previously described ${ }^{20,31}$. Blots were probed overnight at $4{ }^{\circ} \mathrm{C}$ with rabbit primary antibody against $\mathrm{AR}(1: 1000$, Abcam, cat\# ab133273, RRID:AB_11156085) in SignalBoost Immunoreaction Enhancer (Merck Millipore, Cat\# 407207) followed by $1 \mathrm{~h}$ room temperature incubation with StarBright Blue 700 goat anti-rabbit secondary antibody (1:5000, Bio-Rad, Cat\# 12004161, RRID:AB_2721073). For analysis, background adjusted AR band intensity was normalised to total lane protein intensity using Image Lab 6.0 software (Bio-Rad, www.bio-rad.com/ en-au/product/image-lab-software, RRID:SCR_014210). Average group values were then expressed fold relative to averaged WT control group values (expressed as 1.0).

Immunohistochemistry. Lumbar spinal cord was cryosectioned at $20 \mu \mathrm{m}$ and slide mounted onto poly-L-lysine coated glass slides. Citrate antigen retrieval was performed as previously described ${ }^{31}$. For fluorescent detection immunostaining was performed as previously described ${ }^{31}$ with the following primary antibodies: rabbit anti-AR (1:200, Abcam, Cat\# ab133273) and goat anti-ChAT (1:200, Millipore, Cat\# AB144P, RRID:AB_2079751). The following secondary antibodies were incubated for $2 \mathrm{~h}$ at room temperature; donkey biotinylated-anti-rabbit (1:200, Jackson ImmunoResearch Cat\# 711-065-152, RRID:AB_2340593), streptavidin Alexa Fluor-488 (1:200, Jackson ImmunoResearch Cat\# 016-540-084, RRID:AB_2337249) and anti-goat DyLight-550 (1:200, Thermo Fisher Scientific Cat\# SA5-10087, RRID:AB_2556667). Hoechst 33342 (Invitrogen) DNA stain was incubated for $15 \mathrm{~min}$ at $1 \mu \mathrm{g} / \mathrm{ml}$. All images were captured on a Zeiss AxioObserver Z1 (Carl Zeiss Pty Ltd, North Ryde, Australia). For chromogenic DAB detection, sections were blocked for 15 min in $0.5 \%$ hydrogen peroxide in PBS and $1 \mathrm{~h}$ at room temperature in animal-free blocking reagent (Cell Signalling Technology, Cat\# 15019). Rabbit anti-AR (as described above) was incubated at $4{ }^{\circ} \mathrm{C}$ for $48 \mathrm{~h}$ in SignalStain antibody diluent (Cell Signaling Technology, Cat\# 8112). SignalStain Boost IHC Detection Reagent (HRP, rabbit) (Cell Signaling Technology, Cat\# 8114) was used as secondary detection and DAB colorimetric reaction performed using SignalStain DAB Substrate Kit (Cell Signaling Technology, Cat\# 8059). Images were acquired on a Leica DMLB2 microscope.

Behavioural analyses and survival assessment. For aging of $\mathrm{AR}^{\text {flox }} \mathrm{x}$ NesCre mouse cohorts $(\mathrm{n}=12-19$ from 2 months age onwards), animals were weighed fortnightly until 24 months of age. Mice reaching endpoint criterion included decline in physical condition and/or progressive non-recoverable weight loss amounting to $20 \%$ of peak weight. The survival of male $\mathrm{AR}^{\mathrm{Q} 24}$ mice was determined across a cohort of 62 mice to age 150 days. In SOD $1^{\mathrm{G} 93 \mathrm{~A}}$ mouse survival studies mice were weighed once weekly and assessed for motor function. Locomotion was assessed using an accelerating rotarod (Rota-Rod 47600, Ugo Basile, Italy) as previously reported ${ }^{20}$. Muscular strength was assessed using a grip strength meter (BIO-G53, Bioseb, US). Mice were suspended by the tail and lowered onto a slanted metal grid until all four paws briefly made contact. Mice were then pulled from the mesh grid in parallel to the attached force transducer in a rapid, smooth and continuous motion. Force was measured in grams and an average of five successive pulls was reported for each mouse. The appearance of disease onset was determined retrospectively using the age of maximal body weight. Clinical endpoint for survival was defined as onset of paralysis in the hindlimbs and/or a cumulative loss of $20 \%$ peak body weight. In the $\mathrm{AR}^{\text {flox }} \mathrm{x}$ NesCre $\mathrm{x}$ SOD $1^{\mathrm{G} 93 \mathrm{~A}}$ cohort, $\mathrm{n}=9-13$ mice per group reached clinical endpoint and were included in the dataset. Once mouse from nARKO group died at 108 days prior to any symptom onset and was included as a censored value. In the $\mathrm{AR}^{\mathrm{Q} 24} \times \mathrm{SOD} 1^{\mathrm{G} 93 \mathrm{~A}}$ cohort group sizes included in survival data analysis were $\mathrm{n}=20 \mathrm{male}$ SOD1 ${ }^{\mathrm{G} 93 \mathrm{~A}}, \mathrm{n}=15$ male SOD1 ${ }^{\mathrm{G} 93 \mathrm{~A}}: \mathrm{AR}^{\mathrm{Q} 24}, \mathrm{n}=12$ female SOD1 ${ }^{\mathrm{G} 93 \mathrm{~A}}$ and $\mathrm{n}=12$ female SOD1 ${ }^{\mathrm{G} 93 \mathrm{~A}}: \mathrm{AR}^{\mathrm{Q} 24}$.

Data analyses and statistics. Transcript, western blot, tissue weight and peak body weight data from $\mathrm{AR}^{\text {flox }} \mathrm{x}$ NesCre cross mice were analysed by one-way ANOVA with Dunnett's multiple comparison comparing each genotype against WT. Western blot and peak body weight data from $\mathrm{AR}^{\mathrm{Q} 24}$ mice were analysed by two-way ANOVA with Sidak's multiple comparison test for sex and genotype effects where F-value indicated a significant effect $(P<0.05)$. Cumulative body weight gain plots were analysed by either mixed-effects analysis (for 24 month aged mice) or two-way ANOVA with repeated measures and Tukey's multiple comparison test for main genotype effect. Survival data was analysed by Log-rank (Mantel-Cox) test. All other single genotype comparisons were performed using two-tailed Student's t-test. Statistical analysis were performed using GraphPad Prism 8.3 (San Diego, CA, USA) and data presented as mean \pm SEM unless otherwise stated.

Received: 10 December 2020; Accepted: 30 March 2021

Published online: 29 April 2021

\section{References}

1. Taylor, J. P., Brown, R. H. Jr. \& Cleveland, D. W. Decoding ALS: From genes to mechanism. Nature 539, 197-206 (2016).

2. McCombe, P. A. \& Henderson, R. D. Effects of gender in amyotrophic lateral sclerosis. Gend. Med. 7, 557-570 (2010).

3. Rooney, J. et al. C9orf72 expansion differentially affects males with spinal onset amyotrophic lateral sclerosis. J. Neurol. Neurosurg. Psychiatry 88, 281 (2017). 
4. Trojsi, F. et al. Comparative analysis of C9orf72 and sporadic disease in a large multicenter ALS population: The effect of male sex on survival of C9orf72 positive patients. Front. Neurosci. 13, 485 (2019).

5. Blecher, R. et al. Contact sports as a risk factor for amyotrophic lateral sclerosis: A systematic review. Global Spine J. 9, 104-118 (2019).

6. Scarmeas, N., Shih, T., Stern, Y., Ottman, R. \& Rowland, L. P. Premorbid weight, body mass, and varsity athletics in ALS. Neurology 59, 773-775 (2002).

7. Visser, A. E. et al. Multicentre, cross-cultural, population-based, case-control study of physical activity as risk factor for amyotrophic lateral sclerosis. J. Neurol. Neurosurg. Psychiatry 89, 797-803 (2018).

8. Beghi, E. Are professional soccer players at higher risk for ALS?. Amyotroph. Lateral Scler. Frontotemp. Degener. 14, 501-506 (2013).

9. Vivekananda, U. et al. Low index-to-ring finger length ratio in sporadic ALS supports prenatally defined motor neuronal vulnerability. J. Neurol. Neurosurg. Psychiatry 82, 635-637 (2011).

10. Manning, J. T., Morris, L. \& Caswell, N. Endurance running and digit ratio (2D:4D): Implications for fetal testosterone effects on running speed and vascular health. Am. J. Hum. Biol. 19, 416-421 (2007).

11. Giffin, N. A., Kennedy, R. M., Jones, M. E. \& Barber, C. A. Varsity athletes have lower 2D:4D ratios than other university students. J. Sports Sci. 30, 135-138 (2012).

12. Hardiman, O. et al. Amyotrophic lateral sclerosis. Nat. Rev. Dis. Primers 3, 17071 (2017).

13. La Spada, A. R., Wilson, E. M., Lubahn, D. B., Harding, A. E. \& Fischbeck, K. H. Androgen receptor gene mutations in X-linked spinal and bulbar muscular atrophy. Nature 352, 77-79 (1991).

14. Pfohl, S. R., Halicek, M. T. \& Mitchell, C. S. Characterization of the contribution of genetic background and gender to disease progression in the SOD1 G93A mouse model of amyotrophic lateral sclerosis: A meta-analysis. J. Neuromuscul. Dis. 2, 137-150 (2015).

15. Hatzipetros, T. et al. C57BL/6J congenic Prp-TDP43A315T mice develop progressive neurodegeneration in the myenteric plexus of the colon without exhibiting key features of ALS. Brain Res. 1584, 59-72 (2014).

16. Turner, B. J. \& Talbot, K. Transgenics, toxicity and therapeutics in rodent models of mutant SOD1-mediated familial ALS. Prog. Neurobiol. 85, 94-134 (2008).

17. Sheean, R. K. et al. Effect of thymic stimulation of CD4+ T cell expansion on disease onset and progression in mutant SOD1 mice. J. Neuroinflamm. 12, 40 (2015).

18. Hayes-Punzo, A. et al. Gonadectomy and dehydroepiandrosterone (DHEA) do not modulate disease progression in the G93A mutant SOD1 rat model of amyotrophic lateral sclerosis. Amyotroph. Lateral Scler. 13, 311-314 (2012).

19. Mostaghel, E. A. et al. Contribution of adrenal glands to intratumor androgens and growth of castration-resistant prostate cancer. Clin. Cancer Res. 25, 426-439 (2019).

20. McLeod, V. M. et al. Androgen receptor antagonism accelerates disease onset in the SOD1(G93A) mouse model of amyotrophic lateral sclerosis. Br. J. Pharmacol. 176, 2111-2130 (2019).

21. Yoo, Y. E. \& Ko, C. P. Dihydrotestosterone ameliorates degeneration in muscle, axons and motoneurons and improves motor function in amyotrophic lateral sclerosis model mice. PLoS ONE 7, e37258 (2012).

22. Aggarwal, T. et al. Androgens affect muscle, motor neuron, and survival in a mouse model of SOD1-related amyotrophic lateral sclerosis. Neurobiol. Aging 35, 1929-1938 (2014).

23. Tronche, F. et al. Disruption of the glucocorticoid receptor gene in the nervous system results in reduced anxiety. Nat. Genet. 23, 99-103 (1999).

24. Raskin, K. et al. Conditional inactivation of androgen receptor gene in the nervous system: Effects on male behavioral and neuroendocrine responses. J. Neurosci. 29, 4461-4470 (2009).

25. Davey, R. A. et al. Androgen action via the androgen receptor in neurons within the brain positively regulates muscle mass in male mice. Endocrinology 158, 3684-3695 (2017).

26. Chakraborty, P. et al. Androgen-dependent sertoli cell tight junction remodeling is mediated by multiple tight junction components. Mol. Endocrinol. 28, 1055-1072 (2014).

27. Holdcraft, R. W. \& Braun, R. E. Androgen receptor function is required in Sertoli cells for the terminal differentiation of haploid spermatids. Development 131, 459-467 (2004).

28. MacLean, H. E. et al. A floxed allele of the androgen receptor gene causes hyperandrogenization in male mice. Physiol. Genomics 33, 133-137 (2008).

29. Katsuno, M. et al. Testosterone reduction prevents phenotypic expression in a transgenic mouse model of spinal and bulbar muscular atrophy. Neuron 35, 843-854 (2002).

30. Galichet, C., Lovell-Badge, R. \& Rizzoti, K. Nestin-Cre mice are affected by hypopituitarism, which is not due to significant activity of the transgene in the pituitary gland. PLOS ONE 5, el1443 (2010).

31. McLeod, V.M., et al. Dysregulation of steroid hormone receptors in motor neurons and glia associates with disease progression in ALS mice. Endocrinology 161(2020).

32. Wu, Y. et al. Identification of androgen response elements in the insulin-like growth factor I upstream promoter. Endocrinology 148, 2984-2993 (2007).

33. Yoshida, T. \& Delafontaine, P. Mechanisms of IGF-1-mediated regulation of skeletal muscle hypertrophy and atrophy. Cells 9 (2020).

34. Kaspar, B. K., Llado, J., Sherkat, N., Rothstein, J. D. \& Gage, F. H. Retrograde viral delivery of IGF-1 prolongs survival in a mouse ALS model. Science 301, 839-842 (2003).

35. Juntti, S. A. et al. The androgen receptor governs the execution, but not programming, of male sexual and territorial behaviors. Neuron 66, 260-272 (2010).

36. Dubois, N. C., Hofmann, D., Kaloulis, K., Bishop, J. M. \& Trumpp, A. Nestin-Cre transgenic mouse line Nes-Crel mediates highly efficient Cre/loxP mediated recombination in the nervous system, kidney, and somite-derived tissues. Genesis 44, 355-360 (2006).

37. Harno, E., Cottrell, E. C. \& White, A. Metabolic pitfalls of CNS Cre-based technology. Cell Metab. 18, 21-28 (2013).

38. Ophoff, J. et al. Androgen signaling in myocytes contributes to the maintenance of muscle mass and fiber type regulation but not to muscle strength or fatigue. Endocrinology 150, 3558-3566 (2009).

39. Chambon, C. et al. Myocytic androgen receptor controls the strength but not the mass of limb muscles. Proc. Natl. Acad. Sci. US A 107, 14327-14332 (2010).

40. Monks, D. A. et al. Overexpression of wild-type androgen receptor in muscle recapitulates polyglutamine disease. Proc. Natl. Acad. Sci. U S A 104, 18259-18264 (2007).

41. Kee, A. J., Gunning, P. W. \& Hardeman, E. C. Diverse roles of the actin cytoskeleton in striated muscle. J. Muscle Res. Cell Motil. 30, 187-197 (2009).

42. Dupuis, L. \& Loeffler, J. P. Neuromuscular junction destruction during amyotrophic lateral sclerosis: insights from transgenic models. Curr. Opin. Pharmacol. 9, 341-346 (2009).

43. Wang, M. et al. Both endogenous and exogenous testosterone decrease myocardial STAT3 activation and SOCS3 expression after acute ischemia and reperfusion. Surgery 146, 138-144 (2009).

44. Verzola, D. et al. Androgen-mediated apoptosis of kidney tubule cells: role of c-Jun amino terminal kinase. Biochem. Biophys. Res. Commun. 387, 531-536 (2009). 
45. Yeap, B.B., Dwivedi, G., Chih, H.J. \& Reid, C. Androgens and cardiovascular disease in men. In Endotext (eds. Feingold, K.R., et al.) (South Dartmouth, 2000).

46. Chang, C., Yeh, S., Lee, S. O. \& Chang, T. M. Androgen receptor (AR) pathophysiological roles in androgen-related diseases in skin, bone/muscle, metabolic syndrome and neuron/immune systems: Lessons learned from mice lacking AR in specific cells. Nucl. Recept. Signal 11, e001 (2013).

47. Forgie, M. L. \& Kolb, B. Manipulation of gonadal hormones in neonatal rats alters the morphological response of cortical neurons to brain injury in adulthood. Behav. Neurosci. 117, 257-262 (2003).

48. Weisz, J. \& Ward, I. L. Plasma testosterone and progesterone titers of pregnant rats, their male and female fetuses, and neonatal offspring. Endocrinology 106, 306-316 (1980).

49. Swift-Gallant, A., Coome, L. A., Ramzan, F. \& Monks, D. A. Nonneural androgen receptors affect sexual differentiation of brain and behavior. Endocrinology 157, 788-798 (2016).

50. Heitzer, M. et al. Administration of 17beta-estradiol improves motoneuron survival and down-regulates inflammasome activation in male SOD1(G93A) ALS mice. Mol. Neurobiol. 54, 8429-8443 (2017).

51. Kim, J., Kim, T. Y., Cho, K. S., Kim, H. N. \& Koh, J. Y. Autophagy activation and neuroprotection by progesterone in the G93ASOD1 transgenic mouse model of amyotrophic lateral sclerosis. Neurobiol. Dis. 59, 80-85 (2013).

52. Groeneveld, G. J. et al. Ovariectomy and 17beta-estradiol modulate disease progression of a mouse model of ALS. Brain Res. 1021, 128-131 (2004).

53. Snell, D. M. \& Turner, J. M. A. Sex chromosome effects on male-female differences in mammals. Curr. Biol. 28, R1313-R1324 (2018).

54. Voskuhl, R. R., Sawalha, A. H. \& Itoh, Y. Sex chromosome contributions to sex differences in multiple sclerosis susceptibility and progression. Mult. Scler. 24, 22-31 (2018).

55. Golden, L.C., et al. Parent-of-origin differences in DNA methylation of X chromosome genes in T lymphocytes. Proc. Natl. Acad. Sci. U S A (2019).

56. Lee, J. et al. Sex-specific neuroprotection by inhibition of the Y-chromosome gene, SRY, in experimental Parkinson's disease. Proc. Natl. Acad. Sci. U S A 116, 16577-16582 (2019).

57. Declercq, J. et al. Metabolic and behavioural phenotypes in nestin-cre mice are caused by hypothalamic expression of human growth hormone. PLoS ONE 10, e0135502 (2015).

58. Briancon, N., McNay, D. E., Maratos-Flier, E. \& Flier, J. S. Combined neural inactivation of suppressor of cytokine signaling-3 and protein-tyrosine phosphatase-1B reveals additive, synergistic, and factor-specific roles in the regulation of body energy balance. Diabetes 59, 3074-3084 (2010).

59. Mullur, R., Liu, Y. Y. \& Brent, G. A. Thyroid hormone regulation of metabolism. Physiol. Rev. 94, 355-382 (2014).

60. Bouteloup, C. et al. Hypermetabolism in ALS patients: an early and persistent phenomenon. J. Neurol. 256, 1236-1242 (2009).

61. Steyn, F. J. et al. Hypermetabolism in ALS is associated with greater functional decline and shorter survival. J. Neurol. Neurosurg. Psychiatry 89, 1016-1023 (2018).

62. Steyn, F. J. et al. Impairments to the GH-IGF-I axis in hSOD1G93A mice give insight into possible mechanisms of GH dysregulation in patients with amyotrophic lateral sclerosis. Endocrinology 153, 3735-3746 (2012).

63. Pharaoh, G. et al. Metabolic and stress response changes precede disease onset in the spinal cord of mutant SOD1 ALS mice. Front. Neurosci. 13, 487 (2019).

64. Scaricamazza, S., et al. Skeletal-muscle metabolic reprogramming in ALS-SOD1(G93A) mice predates disease onset and is a promising therapeutic target. iScience 23, 101087 (2020).

65. Steyn, F. J. et al. Growth hormone secretion is correlated with neuromuscular innervation rather than motor neuron number in early-symptomatic male amyotrophic lateral sclerosis mice. Endocrinology 154, 4695-4706 (2013).

66. Zurlo, F., Larson, K., Bogardus, C. \& Ravussin, E. Skeletal muscle metabolism is a major determinant of resting energy expenditure. J. Clin. Invest. 86, 1423-1427 (1990).

67. Fergani, A. et al. Increased peripheral lipid clearance in an animal model of amyotrophic lateral sclerosis. J. Lipid Res. 48, 1571-1580 (2007).

68. Fergani, A. et al. A mutation in the dynein heavy chain gene compensates for energy deficit of mutant SOD1 mice and increases potentially neuroprotective IGF-1. Mol. Neurodegener. 6, 26 (2011).

69. McDonald, T.S., Kumar, V., Fung, J.N., Woodruff, T.M. \& Lee, J.D. Glucose clearance and uptake is increased in the SOD $1<$ sub $>$ G93A $</$ sub $>$ mouse model of amyotrophic lateral sclerosis through an insulin-independent mechanism. bioRxiv:2020.2008.2002.233411 (2020).

70. McLeod, V.M., Cuic, B., Chiam, M.D.F., Lau, C.L. \& Turner, B.J. Exploring germline recombination in Nestin-Cre transgenic mice using floxed androgen receptor. Genesis, e23390 (2020).

\section{Author contributions}

D.T. and V.M. coordinated and performed experiments and analysed data. V.M. wrote the manuscript. M.C. and N.W. assisted in experiments and analysis. W.B. and B.T. provided supervision and BT conceived the study idea. All authors contributed to and approved the final manuscript.

\section{Funding}

Funding for this project was provided by the Australian NHMRC (Project Grants 1104295, 1104299), Stafford Fox Medical Research Foundation, MND Research Institute of Australia (Ted Dimmick Memorial MND Research Grant). VM was supported by a MND Research Institute of Australia PhD Scholarship Top-Up Grant, BT was supported by an NHMRC-ARC Dementia Research Leadership Fellowship (1137024).

\section{Competing interests}

The authors declare no competing interests.

\section{Additional information}

Supplementary Information The online version contains supplementary material available at https://doi.org/ 10.1038/s41598-021-88415-0.

Correspondence and requests for materials should be addressed to B.J.T.

Reprints and permissions information is available at www.nature.com/reprints.

Publisher's note Springer Nature remains neutral with regard to jurisdictional claims in published maps and institutional affiliations. 
(c) (i) Open Access This article is licensed under a Creative Commons Attribution 4.0 International cc) License, which permits use, sharing, adaptation, distribution and reproduction in any medium or format, as long as you give appropriate credit to the original author(s) and the source, provide a link to the Creative Commons licence, and indicate if changes were made. The images or other third party material in this article are included in the article's Creative Commons licence, unless indicated otherwise in a credit line to the material. If material is not included in the article's Creative Commons licence and your intended use is not permitted by statutory regulation or exceeds the permitted use, you will need to obtain permission directly from the copyright holder. To view a copy of this licence, visit http://creativecommons.org/licenses/by/4.0/.

(C) The Author(s) 2021 